\title{
Induction of Genes Expressed in Endothelial Cells of the Corpus Callosum in the Chronic Cerebral Hypoperfusion Rat Model
}

\author{
Yasuhiro Aso ${ }^{a}$ Kenichiro Nakamura ${ }^{a}$ Noriyuki Kimura ${ }^{a} \quad$ Makoto Takemaru $^{a}$ \\ Ryuki Arakawa $^{a}$ Minoru Fujiki ${ }^{b}$ Teruyuki Hirano ${ }^{a}$ Toshihide Kumamoto $^{a}$ \\ Etsuro Matsubara ${ }^{a}$
}

Departments of a Neurology and ${ }^{b}$ Neurosurgery, Faculty of Medicine, Oita University, Oita, Japan

\author{
Key Words \\ Chronic cerebral hypoperfusion - White matter - Gene \\ expression · Endothelial cell · Neurovascular dysfunction
}

novel genes that may be associated with WML development in the chronic cerebral hypoperfusion rat model, and suggest an important role of neurovascular dysfunction in the pathophysiology.

(c) 2016 S. Karger AG, Basel

\begin{abstract}
Background: Cerebrovascular white matter lesions (WMLs) are associated with cognitive impairment in patients with subcortical vascular dementia. We performed a comprehensive gene expression analysis to elucidate genes associated with WML development in a chronic cerebral hypoperfusion rat model. Methods: Brains of rats with bilateral carotid ligation ( $2 \mathrm{VO}, \mathrm{n}=10$ ) and sham-operated rats ( $\mathrm{n}=5-10 /$ group) were removed on days 1,7 , or 28 after surgery. Total RNA isolated from the corpus callosum was evaluated by microarray analysis and quantitative reverse transcription-polymerase chain reaction. Results: On days 7 and 28, WMLs exhibited histologic changes. On day 7, 16 genes were differentially expressed between groups. mRNA levels of Ptprb, Kcnj8, Crispld2, Bcl6b, and Gja5 were differentially expressed in $2 \mathrm{VO}$ rats on day 7 , but then returned to normal, whereas mRNA levels of Vwf and Trappc6a were upregulated after day 7. Immunohistochemistry showed that GJA5 and VWF were detected in endothelial cells, KCNJ8 in endothelial cells and astrocytes, CRISPLD2 in neurons and astrocytes, and TRAPPC6A in neurons. Conclusion: Our findings indicate
\end{abstract}

\section{KARGER}

(c) 2016 S. Karger AG, Basel

E-Mail karger@karger.com

www.karger.com/pat

\section{Introduction}

Cerebral white matter lesions (WMLs), characterized by hyperintense signals on T2-weighted magnetic resonance images, are observed in healthy elderly people and patients with subcortical vascular dementia [1-5]. These WMLs are thought to be associated with cognitive impairment $[2,6]$. Neuropathologic changes of WMLs are characterized by rarefaction, demyelination, gliosis, microglial activation, and axonal loss [7-10]. Although the pathogenesis of WMLs remains unclear, some types of WMLs may be due to ischemic brain injury [11]. Experimentally, chronic cerebral hypoperfusion induced by permanent occlusion of the bilateral common carotid arteries in the rat causes WMLs with neuropathologic changes very similar to those of WMLs in patients with chronic cerebrovascular disease such as subcortical vascular dementia [12-17]. This rat model of chronic cerebral hypoperfusion gradually develops impairments of 
visuospatial learning, fear conditioning, and nonspatial memory during the chronic phase $[12,18-20]$ and is therefore commonly used to represent ischemic WMLassociated diseases such as subcortical vascular dementia $[12,21]$. Although cerebral ischemia is thought to trigger WML development in the chronic cerebral hypoperfusion rat model, the pathogenetic mechanisms remain unclear. Decreased cerebral blood flow (CBF) during ischemia activates or inhibits the expression of various genes that encode proteins that regulate ischemic processes. The identification of genes associated with WML development may contribute not only to elucidate the pathomechanism of WMLs but also biomarkers and therapeutic targets of ischemic WML-associated diseases. In the present study, we performed comprehensive gene expression microarray analyses to investigate genes associated with early-stage development of WMLs induced by chronic cerebral hypoperfusion in the rat.

\section{Materials and Methods}

\section{Animals and Histologic Analysis}

All experiments were performed in accordance with the Japanese law for the humane treatment and management of animals, standards relating to the care and management of laboratory animals and relief of pain, and were approved by the Ethics Committee of Animal Research at Oita University (permission No. K017002). Male Wistar rats ( $\mathrm{n}=48$; Kyudo Co, Saga, Japan) weighing 274-392 g (9 weeks old) were used in this study. The animals were deeply anesthetized by intraperitoneal injection of sodium pentobarbital (40 mg/kg). During surgery, a heat lamp was applied to maintain body temperature. Through a midline cervical incision, the bilateral common carotid arteries were carefully separated from the cervical sympathetic and vagal nerves, double-ligated with 5-0 silk sutures, and cut between the ligation (2VO). The sham-operated animals underwent similar procedures, except that the bilateral common carotid arteries were not occluded. After surgery, the rats were kept in cages with food and water available ad libitum. On days 1, 7, and 28 after surgery, a subgroup of animals was deeply anesthetized with sodium pentobarbital and transcardially perfused with $0.9 \%$ saline followed by $4 \%$ paraformaldehyde in $0.01 \mathrm{M}$ phosphate buffer ( $\mathrm{pH} 7.4$ ). The brains were removed and fixed in $4 \%$ paraformaldehyde in $0.01 \mathrm{M}$ phosphate buffer ( $\mathrm{pH} 7.4$ ) for $12 \mathrm{~h}$ at $4^{\circ} \mathrm{C}$, and then coronal brain blocks were embedded in paraffin. Coronal brain sections $(2 \mu \mathrm{m}$ thick) were stained with hematoxylin and eosin. The severity of the WML in the corpus callosum was graded as normal (grade 0 ), mild (grade 1), or marked (grade 2) by two independent investigators blinded to the treatment.

\section{Measurement of $C B F$}

CBF was measured using a laser Doppler flow meter (ALF-21; Advance Co, Inc., Tokyo, Japan) as described previously [22]. Briefly, the rats were deeply anesthetized by intraperitoneal injection with sodium pentobarbital $(40 \mathrm{mg} / \mathrm{kg}$ ) and allowed to respire spontaneously. After incising the scalp on the right side of the head, a probe (LP-CM; Unique Medical, Tokyo, Japan) was placed between the temporal muscle and the lateral aspect of the skull. CBF recordings of $2 \mathrm{VO}(\mathrm{n}=10)$ or sham $(\mathrm{n}=10)$ rats were obtained just before surgery and on days 1, 7, and 28 after surgery.

\section{RNA Extraction}

On days 1, 7, or 28 after surgery, the rats were anesthetized and decapitated, the brain was removed immediately, and the whole corpus callosum was carefully dissected under a stereomicroscope. Tissues were frozen immediately in liquid nitrogen and stored at $-80^{\circ} \mathrm{C}$. Total RNA was extracted from frozen tissues using ISOGEN (Nippon Gene, Tokyo, Japan) and then purified using RNeasy Mini Kit (Qiagen, Valencia, Calif., USA) in accordance with the manufacturer's instructions.

\section{Gene Expression Microarray}

For the gene expression microarray, $300 \mathrm{ng}$ of total RNAs extracted from the corpus callosum tissues of $2 \mathrm{VO}(\mathrm{n}=5)$ or sham $(\mathrm{n}=5)$ rats on day 7 after surgery were subjected to microarray analysis as previously described [23]. Briefly, before hybridization, the quantity and quality of the total RNA were evaluated using a spectrophotometer and a 2100 Bioanalyser (Agilent Technologies, Santa Clara, Calif., USA), respectively. Cy3-labeled cRNA targets were generated using an Agilent Quick Amp Labeling Kit (Agilent Technologies). A rat $44 \mathrm{~K}$ oligoarray was used for hybridization in accordance with the manufacturer's recommendations (Agilent Technologies). A laser confocal scanner (Agilent Technologies) was used to measure signal intensities in the expression microarray analysis. Feature Extraction Software (version 9.5; Agilent Technologies) with the manufacturer's recommended settings was applied for the microarray image analysis.

\section{Gene Expression Analysis}

Analysis of the microarray images was performed with GeneSpring GX10 Software (Agilent Technologies). For comparison among multiple arrays, probe set data were median-normalized per chip. Data were then filtered based on a signal intensity of 100 or greater and containing no flagged values. The 20,791 probe sets remaining after this filtering were used for further statistical evaluation. For the selection of genes differentially expressed between $2 \mathrm{VO}$ and sham rats, probe sets were assessed by the Mann-Whitney $U$ test $(\mathrm{p}<0.05)$. Among these differentially expressed genes, those designated as 'upregulated' were overexpressed more than 1.20 -fold compared with the sham controls, and those designated as 'downregulated' were underexpressed by less than 0.83 -fold compared with the sham controls. Annotations were provided by Agilent Technologies.

\section{Quantitative Reverse Transcription-Polymerase Chain}

\section{Reaction}

Reverse transcription was performed using a Transcriptor first-strand cDNA synthesis kit (Roche Diagnostics, Mannheim, Germany) with random hexamer primers in accordance with the manufacturer's instructions. Quantitative reverse transcriptionpolymerase chain reaction (qRT-PCR) was performed using a LightCycler 480 Realtime PCR System with a Universal probe library and a LightCycler 480 probe master (Roche Diagnostics, Penzberg, Germany) in accordance with the manufacturer's instructions. All the primer sets for genes of interest were designed 
by Roche Diagnostics (online suppl. table 1; for all online suppl. material, see www.karger.com/doi/10.1159/000446876). qRTPCR was performed using the following cycle parameters: 1 cycle of $5 \mathrm{~min}$ at $95^{\circ} \mathrm{C}$ followed by cycles of $10 \mathrm{~s}$ at $95^{\circ} \mathrm{C}, 10 \mathrm{~s}$ at the appropriate annealing temperature, and $1 \mathrm{~s}$ at $72^{\circ} \mathrm{C}$ (online suppl. table 1). TATA-binding protein was used as a control, and relative expression levels were obtained by relative quantification analysis. Dilutions of cDNA synthesized from normal rat corpus callosum were used as standards.

\section{Immunohistochemistry}

Proteins were visualized as described previously [24]. Briefly, paraffin-embedded coronal brain sections $(2 \mu \mathrm{m}$ thick) were deparaffinized and rehydrated using standard protocols. Except for anti-CX40 antibody, sections were immersed in $10 \mathrm{~mm}$ sodium citrate buffer, pH 6.0 (Iatron, Tokyo, Japan) and autoclaved at $120^{\circ} \mathrm{C}$ for $10 \mathrm{~min}$ for antigen retrieval. The sections were treated with $3 \% \mathrm{H}_{2} \mathrm{O}_{2}$ for $20 \mathrm{~min}$ at room temperature (RT) to inactivate the endogenous peroxidase activity. After blocking with $10 \%$ goat or rabbit serum (Nichirei, Tokyo, Japan), the sections were incubated overnight at $4{ }^{\circ} \mathrm{C}$ with the following primary antibodies diluted in diluting solution (Dako, Copenhagen, Denmark): rabbit polyclonal anti-potassium inwardly-rectifying channel, subfamily J, member 8 (KCNJ8, Kir6.1) antibody (1:15,000; Novus Biologicals, Littleton, Colo., USA), rabbit polyclonal anti-Cx40/GJA5 antibody (1:700; Chemicon, Temecula, Calif., USA), rabbit polyclonal anti-vWF antibody (1:1,000; Dako), rabbit polyclonal TRAPPC6A antibody (1:800; Santa Cruz Biotechnology, Dallas, Tex., USA), mouse monoclonal anti-PTPRB antibody (clone 122.2; Abcam, Cambridge, Mass., USA), goat polyclonal anti-Bcl6b antibodies (N-12 and S-13; Santa Cruz Biotechnology), and rabbit immunoglobulin G (IgG; Dako) or mouse IgG (Vector Laboratories Inc.) for the negative control. The sections were then washed with phosphate-buffered saline (PBS) and incubated with biotinylated antirabbit or anti-mouse IgG antibody (Nichirei, Tokyo, Japan) for $1 \mathrm{~h}$ at RT. After washing, the sections were incubated with a solution of avidin-conjugated horseradish peroxidase (Vectastain Elite $\mathrm{ABC}$ kit; Vector Laboratories Inc.) for $15 \mathrm{~min}$ at RT, according to the manufacturer's recommendations, and then washed. Peroxidase activity was detected with $\mathrm{H}_{2} \mathrm{O}_{2}$ /diaminobenzidine substrate solution (Vector Laboratories Inc.), and the sections were counterstained with hematoxylin before dehydration and mounting.

For the antigen competition experiments, prior to immunostaining with the anti-Cx40 antibody, anti-TRAPPC6A antibody, or anti-Bcl6b antibody, the antibodies were preabsorbed with 10 times the amount of the mouse $\mathrm{Cx} 40$ control peptide (AG634; Chemicon), human TRAPPC6A GST fusion protein (ag7373; Proteintech Group, Chicago, Ill., USA), or Bcl6b blocking peptides (N-12 or S-13; Santa Cruz Biotechnology), respectively.

The number of immunoreactive vessels in the corpus callosum was counted and the numerical density of immunoreactive vessels was expressed as the number of vessels per $0.6 \mathrm{~mm}^{2}$.

\section{Double-Labeled Immunofluorescence}

Paraffin-embedded coronal brain sections $(2 \mu \mathrm{m}$ thick) were deparaffinized and rehydrated using standard protocols. For antigen retrieval, the sections were immersed in $10 \mathrm{mM}$ sodium citrate buffer, pH 6.0 (Iatron) and boiled at $100^{\circ} \mathrm{C}$ for $10 \mathrm{~min}$ and cooled to RT. After blocking with $10 \%$ nonfat dry milk in $1 \times$ PBS, the sections were incubated overnight at $4{ }^{\circ} \mathrm{C}$ with a mixture of rabbit polyclonal anti-CRISPLD2 antibody (1:100 dilution; Abgent, San Diego, Calif., USA) and mouse monoclonal anti-GFAP (glial fibrillary acidic protein) antibody (1:200 dilution; Sigma-Aldrich, St. Louis, Mo., USA). After washing, the sections were incubated with a mixture of Alexa Fluor 488-conjugated goat anti-rabbit IgG $(\mathrm{H}+\mathrm{L})$ antibody (Life Technologies, Carlsbad, Calif., USA) and Alexa Fluor 568-conjugated goat anti-mouse $\operatorname{IgG}(\mathrm{H}+\mathrm{L})$ antibody (Life Technologies) for $1 \mathrm{~h}$ at RT. After washing, nuclei were stained with 4'-6-diamidino-2-phenylindole (Life Technologies). The sections were then washed again and mounted. The mounted sections were observed under an LSM710 confocal laser scanning microscope (Carl Zeiss, Oberkochen, Germany).

For competition experiments, prior to immunostaining, antiCRISPLD2 antibody was preabsorbed with an excess amount of CRISPLD2 antibody blocking peptide (BP5570a; Abgent).

\section{Western Blot Analysis}

Frozen tissue sections of the corpus callosum excised from the sham rats or $2 \mathrm{VO}$ rats on day 7 after surgery were lysed in sodium dodecyl sulfate (SDS)-modified RIPA buffer $(0.1 \% \mathrm{w} / \mathrm{v}$ SDS, 40 mM 2-[4-(2-hydroxyethyl)-1-piperazinyl] ethanesulfonic acid$\mathrm{NaOH}-\mathrm{pH} 7.4,1 \% \mathrm{w} / \mathrm{v}$ Nonident p- $40,0.5 \%$ w/v sodium deoxycholate, $150 \mathrm{~mm} \mathrm{NaCl}, 5 \mathrm{~mm}$ EDTA acid, $10 \mathrm{~mm}$ sodium fluoride, $2 \mathrm{mM}$ sodium orthovanadate, and protease inhibitor cocktail; Sigma-Aldrich). After centrifuging at $12,000 \mathrm{rpm}$ for $20 \mathrm{~min}$ at $4^{\circ} \mathrm{C}$, the supernatants were boiled with Laemmli's sample buffer. Protein was measured using the Bio-Rad protein assay kit (Bio-Rad Laboratories, Hercules, Calif., USA); $50 \mu \mathrm{g}$ of total protein were separated on a $12 \%$ SDS-polyacrylamide gel and transferred to a polyvinylidene difluoride membrane (Millipore, Billerica, Mass., USA). After blocking with PBS containing $10 \%$ nonfat dry milk for $1 \mathrm{~h}$, the membrane was incubated overnight at $4{ }^{\circ} \mathrm{C}$ with a rabbit polyclonal anti-CRISPLD2 antibody (diluted 1:500; Abgent) and then incubated for $1 \mathrm{~h}$ at RT with peroxidase-conjugated goat anti-rabbit IgG antibody (diluted 1:70,000; Jackson ImmunoResearch Laboratories, West Grove, Pa., USA). Signals were detected using enhanced chemiluminescence reagents (GE Healthcare, Little Chalfont, UK). The same membranes were reprobed with mouse monoclonal anti- $\alpha$-tubulin antibody (Sigma-Aldrich). For quantification, the signal intensities of CRISPLD2 relative to those of a-tubulin were determined by densitometry using NIH Image J (version 1.62) software.

\section{Statistical Analysis}

All CBF, histologic, immunohistochemistry, and qRT-PCR data are presented as means \pm SD. CBF values were analyzed by analysis of variance and the Tukey-Kramer post hoc test. Statistical analyses of all other data were performed using the Mann-Whitney $\mathrm{U}$ test. A p value $<0.05$ was considered statistically significant.

\section{Results}

\section{Characterization of Chronic Cerebral Hypoperfusion Rat Model}

Figure 1a shows temporal profiles of $\mathrm{CBF}$ values in the bilateral carotid ligation model $(2 \mathrm{VO})$ and sham-operated (sham) groups. Mean CBF values in the $2 \mathrm{VO}$ and sham 
Fig. 1. $\mathrm{CBF}$ and white matter pathology of $2 \mathrm{VO}$ rats. a Temporal profile of CBF. Values are means $\pm S D, n=10$ per group. $* \mathrm{p}<0.05$ compared to the sham-operated group. b-g Photomicrographs of hematoxylin and eosin-stained sections of the paramedian corpus callosum from $2 \mathrm{VO}$ rats (b-d) and sham rats (e-g) on days 1 (b, e), $7(\mathbf{c}, \mathbf{f})$, and $28(\mathbf{d}, \mathbf{g})$ after surgery. Scale bar $=50 \mu \mathrm{m}$.
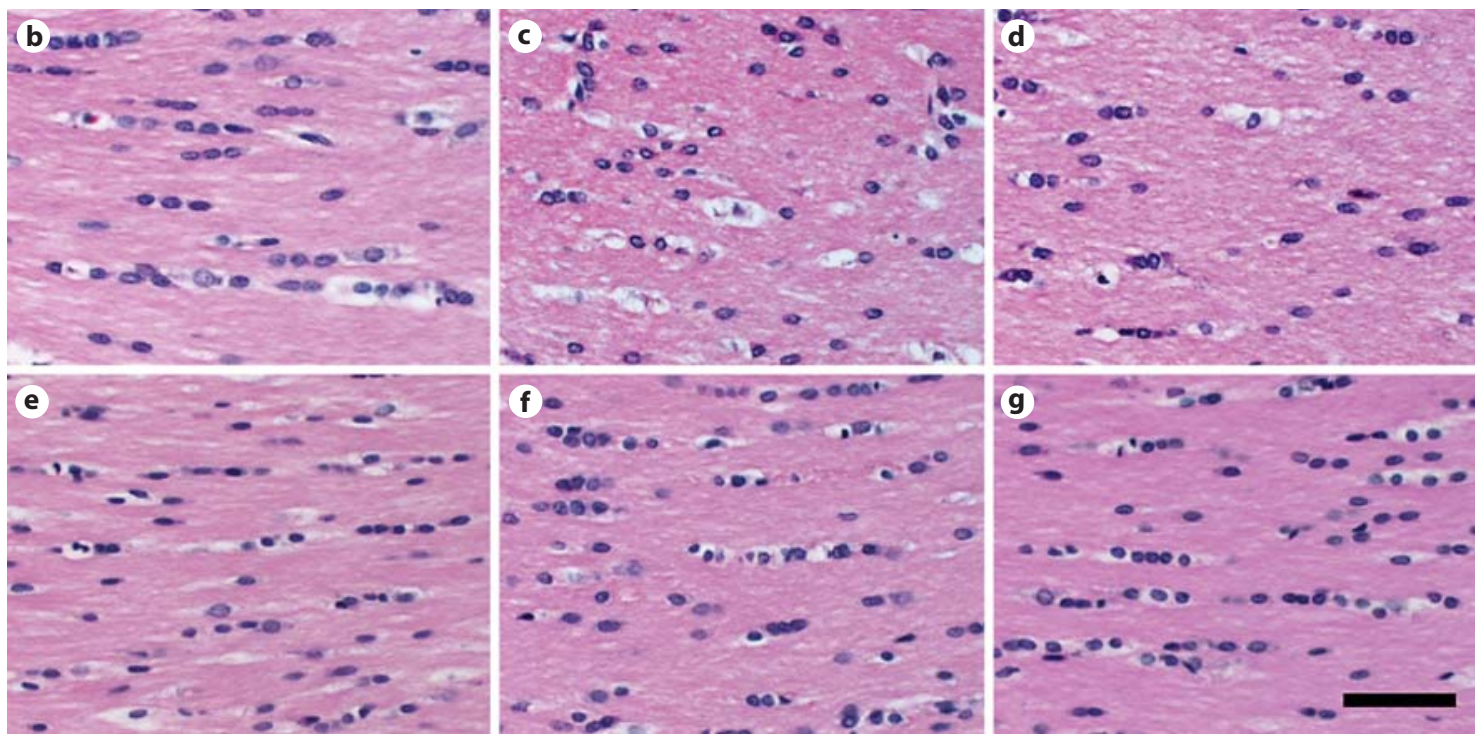

groups were similar before surgery $(36.3 \pm 4.6$ vs. $35.8 \pm$ $3.5 \mathrm{ml} / \mathrm{min} / 100 \mathrm{~g}$ ). Compared with the sham group, mean $\mathrm{CBF}$ values in the $2 \mathrm{VO}$ group were significantly decreased on days 1,7 , and 28 after surgery ( $16.3 \pm 3.9$ vs. $34.5 \pm 3.9$ on day $1 ; 25.5 \pm 3.5$ vs. $36.3 \pm 4.6$ on day $7 ; 29.4 \pm 2.5$ vs. $38.3 \pm 3.4$ on day 28$)$. In the $2 \mathrm{VO}$ group, mean CBF values on day 7 were significantly increased compared with those on day 1 , which were significantly lower than those before surgery. The difference in the mean CBF values between days 7 and 28 was not significant. In the sham group, there was no significant difference in the mean $\mathrm{CBF}$ values among time points.

Histologic analysis revealed no pathologic changes in the brains of sham rats on days 1, 7, and 28 after surgery (fig. 1b-g). On day 1 after surgery, focal acute ischemic regions, consisting of rarefaction and ischemic neurons with eosinophilic cytoplasm and pyknosis, were observed in the cortex or hippocampus in approximately half of the $2 \mathrm{VO}$ rats. The corpus callosum of these rats had mild rar- efaction and some reactive astrocytes (data not shown). The other half of the $2 \mathrm{VO}$ rats on day 1 after surgery showed neither acute ischemic regions in the brain nor any pathologic changes in the corpus callosum (fig. 1b). No infarct or hemorrhage was observed in the brains of the $2 \mathrm{VO}$ rats on days 7 and 28 after surgery. In the corpus callosum of the $2 \mathrm{VO}$ rats on days 7 and 28 after surgery, rarefaction, activation of astrocytes, and loss of oligodendrocytes were observed (WML grading score, $2 \mathrm{VO}$ vs. sham; day $7: 1.3 \pm 0.52$ vs. $0.17 \pm 0.41, \mathrm{p}=0.0104, \mathrm{n}=6$; day 28: $1.0 \pm 0$ vs. $0.13 \pm 0.35, \mathrm{p}=0.0104, \mathrm{n}=5-8$ ) (fig. $1 c, d)$.

Gene Expression Microarray Analysis and qRT-PCR

To identify genes associated with WMLs in the early stage of chronic cerebral hypoperfusion, we performed a gene expression microarray analysis using total RNAs extracted from the corpus callosum on day 7 after surgery. We compared the mRNA expression levels between the 
Table 1. Temporal expression of genes validated by qRT-PCR

\begin{tabular}{|c|c|c|c|c|c|c|c|c|c|}
\hline & \multicolumn{3}{|l|}{1 day } & \multicolumn{3}{|l|}{7 days } & \multicolumn{3}{|l|}{28 days } \\
\hline gja5 & $2.2 \pm 0.74$ & $1.4 \pm 0.79$ & 0.053 & $3.2 \pm 0.66$ & $1.8 \pm 0.55$ & 0.010 & $1.5 \pm 0.42$ & $0.99 \pm 0.22$ & 0.14 \\
\hline crispld2 & $1.0 \pm 0.83$ & $0.24 \pm 0.063$ & 0.0022 & $0.37 \pm 0.12$ & $0.24 \pm 0.054$ & 0.037 & $0.38 \pm 0.073$ & $0.36 \pm 0.12$ & 0.42 \\
\hline cpne4 & $1.9 \pm 2.2$ & $0.90 \pm 0.25$ & 0.49 & $1.1 \pm 0.60$ & $0.69 \pm 0.18$ & 0.26 & $1.5 \pm 0.72$ & $1.3 \pm 0.40$ & 0.52 \\
\hline vwf & $3.4 \pm 1.3$ & $3.6 \pm 1.3$ & 0.11 & $4.3 \pm 1.3$ & $2.7 \pm 0.41$ & 0.011 & $6.0 \pm 1.0$ & $3.8 \pm 1.1$ & 0.028 \\
\hline tns1 & $3.1 \pm 1.4$ & $2.3 \pm 0.52$ & 0.17 & $3.4 \pm 1.7$ & $2.2 \pm 0.16$ & 0.055 & $3.5 \pm 0.80$ & $3.2 \pm 1.0$ & 0.65 \\
\hline kcnj8 & $2.9 \pm 1.8$ & $1.3 \pm 0.26$ & 0.0018 & $1.4 \pm 0.77$ & $1.1 \pm 0.21$ & 0.15 & $2.4 \pm 1.3$ & $2.0 \pm 1.1$ & 0.63 \\
\hline rhbdl3 & $4.3 \pm 2.3$ & $3.4 \pm 0.90$ & 0.44 & $1.1 \pm 0.64$ & $0.79 \pm 0.093$ & 0.34 & $2.3 \pm 0.92$ & $2.2 \pm 1.3$ & 0.75 \\
\hline bcl6b & $4.2 \pm 3.0$ & $2.2 \pm 3.0$ & 0.011 & $1.8 \pm 0.32$ & $2.8 \pm 1.0$ & 0.037 & $2.0 \pm 1.0$ & $2.2 \pm 0.90$ & 0.52 \\
\hline egfl7 & $1.6 \pm 0.90$ & $1.1 \pm 0.13$ & 0.36 & $0.62 \pm 0.24$ & $0.74 \pm 0.15$ & 0.26 & $1.2 \pm 0.34$ & $1.3 \pm 0.29$ & 0.30 \\
\hline avil & $4.3 \pm 1.7$ & $4.6 \pm 3.1$ & 0.75 & $4.0 \pm 2.6$ & $3.5 \pm 1.1$ & 0.87 & $2.4 \pm 1.7$ & $5.2 \pm 5.3$ & 0.92 \\
\hline
\end{tabular}

$2 \mathrm{VO}$ and sham groups with analysis of variance $(\mathrm{p}<0.05)$ and found 16 genes that were significantly differentially expressed more than 1.2-fold in the 2VO group; 10 genes were significantly upregulated and 6 genes were downregulated (online suppl. table 2 ).

The expression levels of these 16 differentially expressed genes in the $2 \mathrm{VO}$ group were further analyzed by qRT-PCR using total RNA extracted from the corpus callosum (table 1). We compared the expression levels of genes between the $2 \mathrm{VO}$ and sham groups on days 1 , 7 , and 28 after surgery. The expression levels of the potassium inwardly-rectifying channel, subfamily J, member 8 (Kcnj8) gene and protein tyrosine phosphatase, receptor type B (Ptprb) gene were significantly increased on day 1 , but were no longer significantly different on days 7 and 28 after surgery in the $2 \mathrm{VO}$ group. The expression level of the cysteine-rich secretory protein LCCL domain containing 2 (Crispld2) gene was significantly increased on days 1 and 7 , but was no longer significantly different on day 28 after surgery in the $2 \mathrm{VO}$ group. The expression level of the gap junction protein alpha5 (Gja5) gene tended to increase on day 1, was significantly increased on day 7 , but was not significantly different on day 28 after surgery in the $2 \mathrm{VO}$ group. The expression level of the B-cell CLL/lymphoma 6, member B (Bcl6b) gene was significantly increased on day 1, significantly decreased on day 7 , and no longer significantly different on day 28 after surgery in the $2 \mathrm{VO}$ group.
The expression level of the von Willebrand factor homo$\log$ (Vwf) gene was not significantly different on day 1 , but was significantly increased on days 7 and 28 after surgery in the $2 \mathrm{VO}$ group. The expression level of the trafficking protein particle complex $6 a$ (Trappc6a) gene was not significantly different on days 1 and 7 , but was significantly increased on day 28 after surgery in the $2 \mathrm{VO}$ group. The expression levels of the eukaryotic translation initiation factor $4 \mathrm{E}$ member 3 (Eif4e3) gene and tensin 1 (Tns1) gene tended to be increased on day 7 , but were not significantly different on days 1 or 28 after surgery in the $2 \mathrm{VO}$ group. The expression levels of the other genes showed no significant differences on days 1,7 , or 28 after surgery.

\section{Immunohistochemistry and Immunofluorescence}

To investigate cells expressing proteins encoded by genes differentially expressed in the $2 \mathrm{VO}$ groups in vivo, we performed immunohistochemical analysis on cerebral tissue sections including the corpus callosum. Cells expressing the KCNJ8, connexin $40(\mathrm{Cx} 40) /$ gap junction alpha-5 (GJA5), vWF, TRAPPC6A, and CRISPLD2 in the cerebrum of $2 \mathrm{VO}$ rats were similar to those in sham rats on days 1,7 , and 28 after surgery. Positive immunoreactivity for KCNJ8 was observed in the vascular endothelial cells (arrowheads in fig. 2a, c) and astrocytes (arrows in fig. 2a, c). The difference in the density of KCNJ8-positive vessels in the corpus cal- 
Fig. 2. Immunohistochemistry for KCNJ8. a-d Representative photomicrographs of the paramedian corpus callosum of sham rats $(\mathbf{a}, \mathbf{b})$ and $2 \mathrm{VO}$ rats $(\mathbf{c}, \mathbf{d})$ on day 1 after surgery. Positive immunoreactivity for KCNJ8 was observed in the vascular endothelial cells (arrowheads) and astrocytes (arrows). No immunoreactivity was observed with the negative control antibody (b, d). Cells expressing KCNJ8 in the cerebrum of the $2 \mathrm{VO}$ rats were similar to those in the sham rats on days 1,7 , and 28 after surgery. Scale bar $=20 \mu \mathrm{m}$.
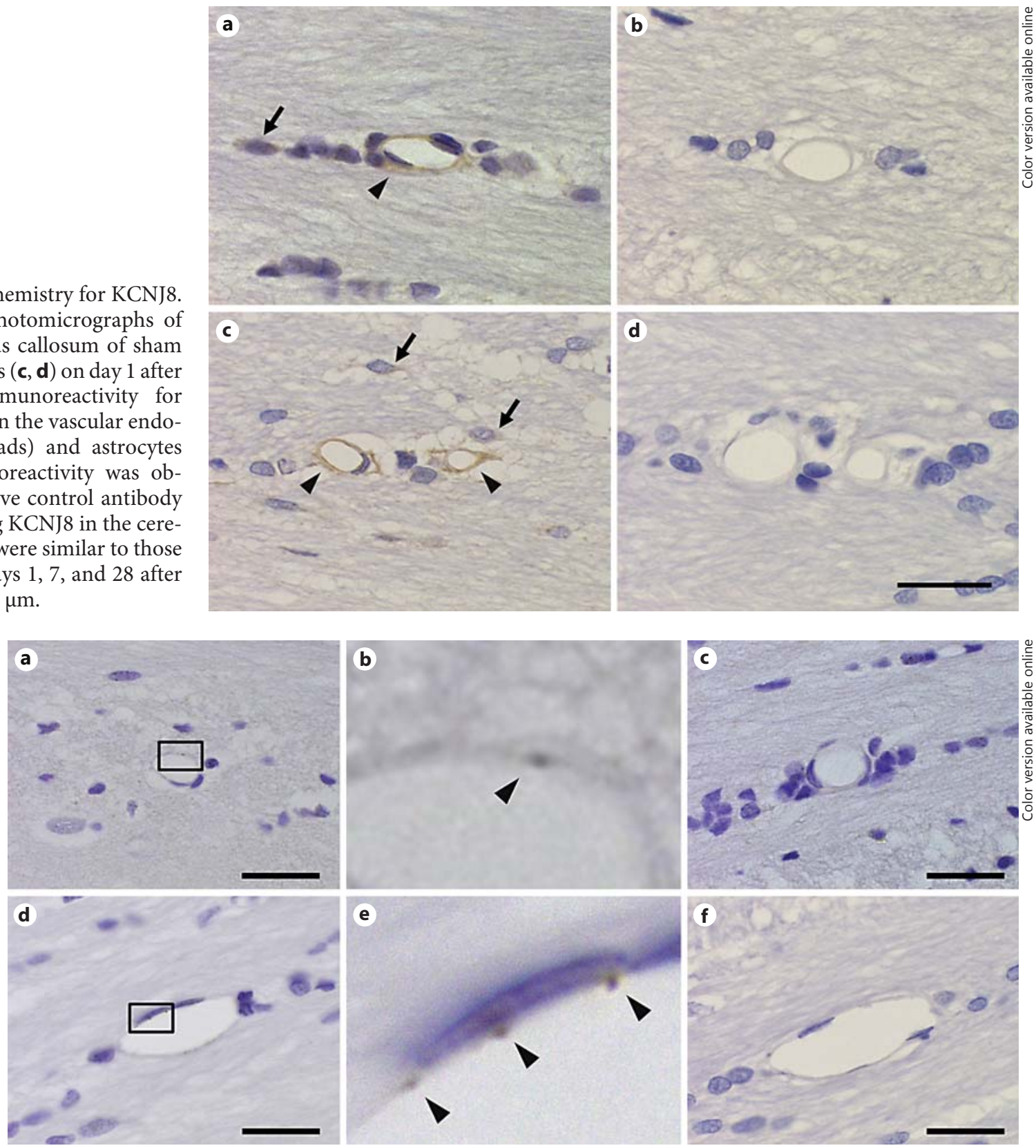

Fig. 3. Immunohistochemistry for Cx40/GJA5. a-f Representative photomicrographs of the paramedian corpus callosum of sham rats $(\mathbf{a}-\mathbf{c})$ and $2 \mathrm{VO}$ rats $(\mathbf{d}-\mathbf{f})$ on day 7 after surgery. $\mathbf{b}$ and $\mathbf{e}$ correspond to the boxed areas in a and $\mathbf{d}$, respectively. Positive immunoreactivity for Cx40/GJA5 was observed in the vascular endo- thelial cells (arrowheads in $\mathbf{b}, \mathbf{e}$ ) and was blocked in the antigen competition experiment (c, f). Cells expressing Cx40/GJA5 in the cerebrum of the $2 \mathrm{VO}$ rats were similar to those of the sham rats on days 1,7 , and 28 after surgery. Scale bar $=20 \mu \mathrm{m}$. losum between the $2 \mathrm{VO}$ and sham rats was not significant $\left(9.7 \pm 3.0\right.$ vs. $8.9 \pm 5.8$ vessels $/ 0.6 \mathrm{~mm}^{2}, \mathrm{p}=0.631$, $\mathrm{n}=6$ ). Positive immunoreactivity for Cx40/GJA5 was observed in the vascular endothelial cells (fig. 3a, b, d, e). The difference in the density of Cx40/GJA5-positive vessels in the corpus callosum between the $2 \mathrm{VO}$ and sham rats was not significant $(1.5 \pm 0.53$ vs. $1.2 \pm 0.57$ vessels $/ 0.6 \mathrm{~mm}^{2}, \mathrm{p}=0.42, \mathrm{n}=6$ ). Positive immunoreactivity for KCNJ8 and Cx40/GJA5 was also detected in the cytoplasm of vascular smooth muscles. Positive im- 
Fig. 4. Immunohistochemistry for vWF. a-d Representative photomicrographs of the paramedian corpus callosum of sham rats $(\mathbf{a}, \mathbf{b})$ and $2 \mathrm{VO}$ rats $(\mathbf{c}, \mathbf{d})$ on day 28 after surgery. Positive immunoreactivity for vWF was observed in the vascular endothelial cells (arrowheads in a, c), while no immunoreactivity was detected with the negative control antibody (b, d). Cells expressing $\mathrm{VWF}$ in the cerebrum of the $2 \mathrm{VO}$ rats were similar to those in the sham rats on days 1,7 , and 28 after surgery. Scale bar $=20 \mu \mathrm{m}$.
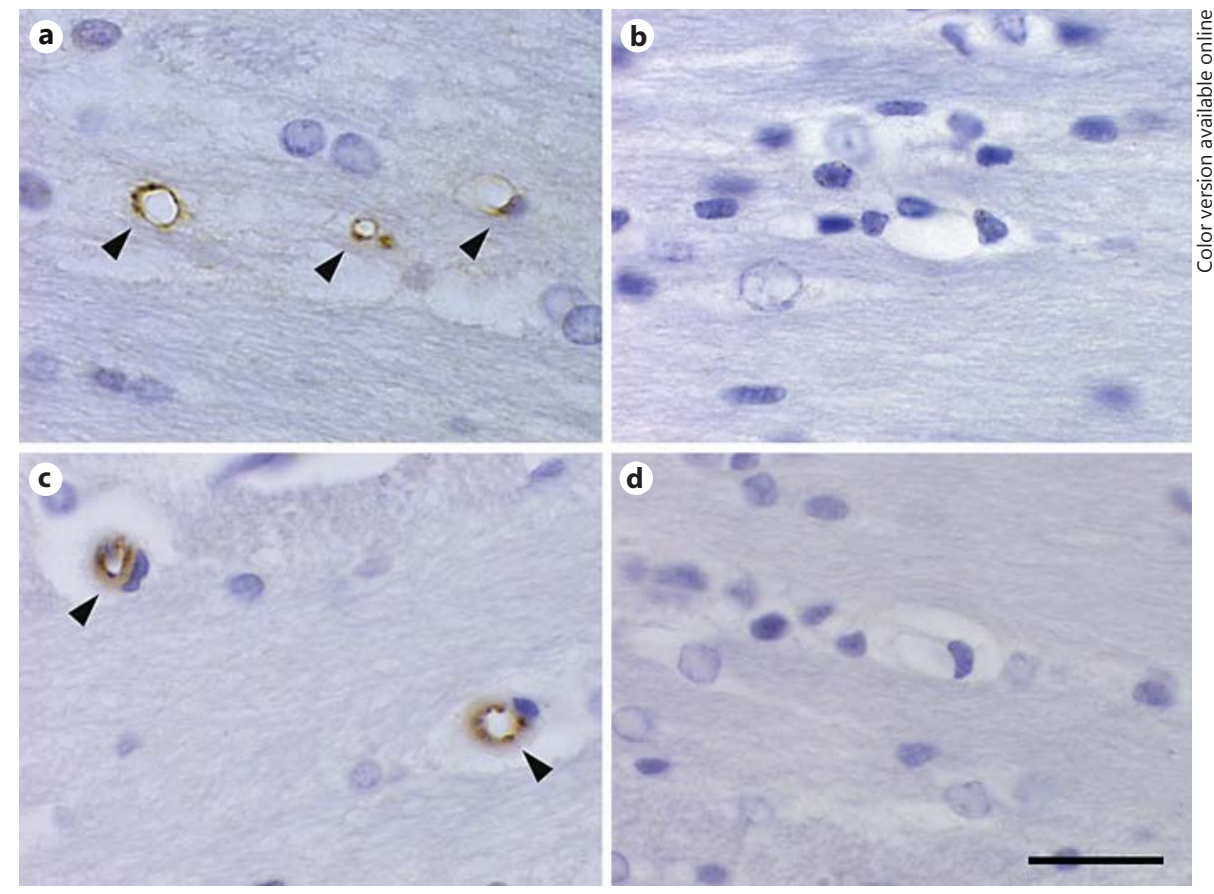

munoreactivity for vWF was detected in the vascular endothelial cells (fig. 4a, c). The difference in the density of vWF-positive vessels in the corpus callosum between the $2 \mathrm{VO}$ and sham rats was not significant (37.0 \pm 11.0 vs. $40.0 \pm 12.1$ vessels $/ 0.6 \mathrm{~mm}^{2}, \mathrm{p}=0.584, \mathrm{n}=6$ ). Positive immunoreactivity for TRAPPC6A was not detected in the corpus callosum, but was detected in the cytoplasm of the pyramidal neurons in the cerebral cortex and hippocampus (fig. 5a, c, e, g). Nonspecific immunoreactivity was unlikely because the positive immunoreactivity was no longer observed in antigen competition experiments (fig. $3 c, f, 5 b, d, f, h$ ) or with negative control antibody (fig. 2b, d, 4b, d). Double-labeled immunofluorescence revealed positive immunoreactivity for CRISPLD2 in the nucleus of GFAP-positive glial cells (indicating astrocytes; fig. 6a-f), GFAPnegative glial cells (fig. 6a-f), and neurons (fig. 6j-o). Nonspecific immunoreactivity was unlikely because the positive immunoreactivity for CRISPLD2 was significantly decreased in antigen competition experiments (fig. 6g-i, 6p-r). Western blotting analysis with the anti-CRISPLD2 antibody revealed no significant difference in the CRISPLD2 protein level relative to $\alpha$-tubulin between the $2 \mathrm{VO}$ rats $(\mathrm{n}=5)$ and sham rats $(\mathrm{n}=6$; fig. $6 \mathrm{~s}, \mathrm{t}$ ). Positive immunoreactivity for Ptprb and Bcl6b was not observed with the antibodies used in this study.

Novel Genes and WML Development in Chronic Cerebral Hypoperfusion Rat

\section{Discussion}

In the present study, we investigated genes associated with early-phase WMLs in the 2VO rat, using a comprehensive gene expression microarray analysis. The corpus callosum serves as the most common and easily delineated region of interest for white matter research in the $2 \mathrm{VO}$ rat [12]. Temporal changes in $\mathrm{CBF}$ values and neuropathologic changes in the corpus callosum of the $2 \mathrm{VO}$ rat in the present study were consistent with previous findings [12]. At 7 days after the $2 \mathrm{VO}$ surgery, CBF values dynamically decreased and then recovered, and neuropathologic changes in the corpus callosum were minimal. After day 7 following 2VO surgery, CBF gradually stabilized, and neuropathologic changes in the corpus callosum were observed. Based on these findings, we performed a comprehensive gene expression analysis using RNA extracted from the corpus callosum on day 7, when $\mathrm{CBF}$ values stabilized and neuropathologic changes in the corpus callosum were observed. Based on the analysis of temporal changes in gene expression by qRT-PCR, genes differentially expressed in the $2 \mathrm{VO}$ group at day 7 were classified into two groups: five genes (Ptprb, Kcnj8, Crispld2, Bcl6b, and Gja5) were upregulated within 7 days after surgery and returned to normal levels after day 7 , and two genes ( Vwf and Trappc6a) were upregulated after day 7 . These findings suggest that the expression of 
Fig. 5. Immunohistochemistry for TRAPPC6A. Representative photomicrographs of the cerebral cortex (a-d) and hippocampus $(\mathbf{e}-\mathbf{h})$ of sham rats $(\mathbf{a}, \mathbf{b}, \mathbf{e}, \mathbf{f})$ and $2 \mathrm{VO}$ rats $(\mathbf{c}, \mathbf{d}, \mathbf{g}, \mathbf{h})$ on day 28 after surgery are shown. Positive immunoreactivity for TRAPPC6A was detected in the cytoplasm of pyramidal neurons. The positive immunoreactivity for TRAPPC6A was blocked in the antigen competition experiments (b, $\mathbf{d}, \mathbf{f}, \mathbf{h})$. Cells expressing TRAPPC6A in the cerebrum of the $2 \mathrm{VO}$ rats were similar to those in the sham rats on days 1,7 , and 28 after surgery. Scale bar $=50 \mu \mathrm{m}$.
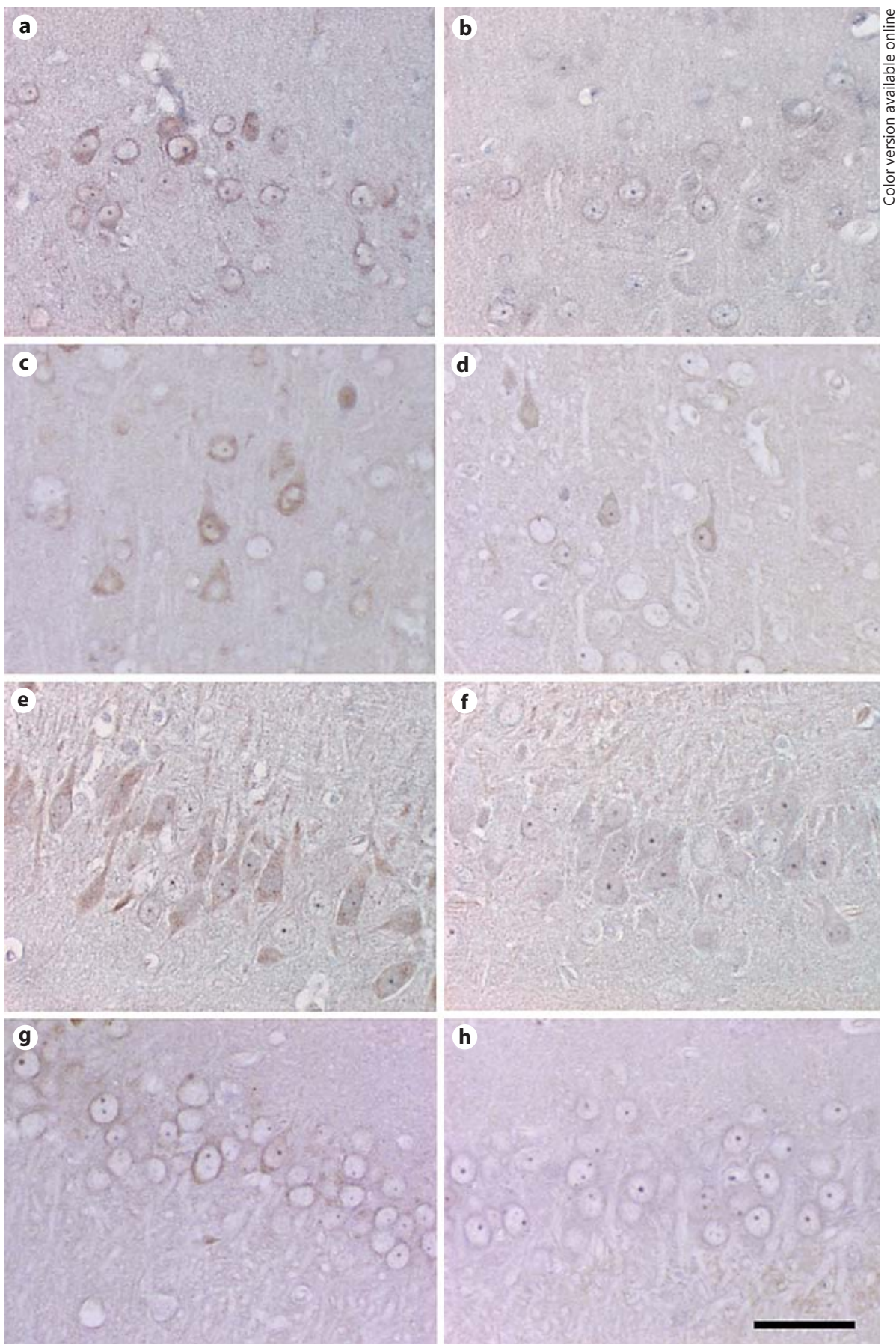

these genes in the corpus callosum of the $2 \mathrm{VO}$ rats was dysregulated in accordance with the degree of changes in the $\mathrm{CBF}$ values and neuropathologic changes in the corpus callosum.

Of the seven genes differentially expressed in the $2 \mathrm{VO}$ rats in the present study, the proteins encoded by Kcnj8,
Gja5, and Vwf genes are expressed in endothelial cells, as shown in the present study, and the Ptprb gene encodes an endothelial-specific membrane protein, vascular endothelial protein tyrosine phosphatase (VE-PTP) [25, $26]$. The cerebral endothelium plays a crucial role in regulating $\mathrm{CBF}$ and in the blood-brain barrier (BBB). Dis- 

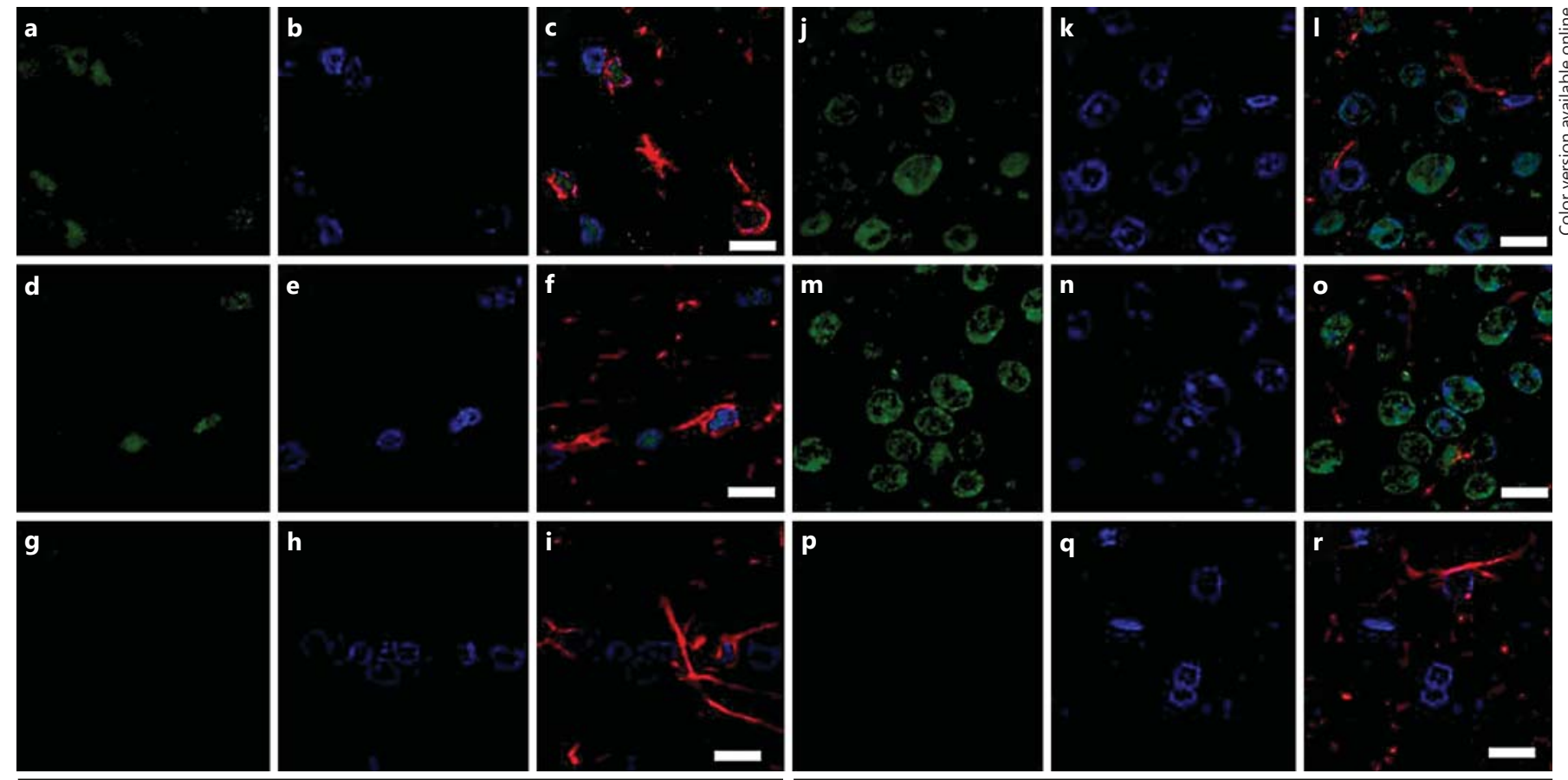

$\mathbf{S}$

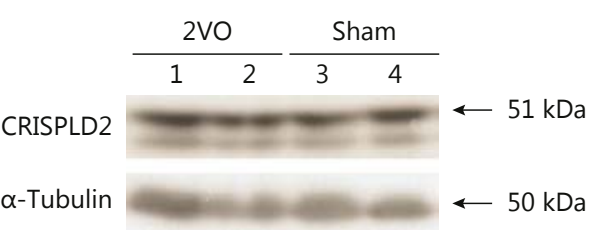

Fig. 6. Expression of CRISPLD2 protein. a-r Immunofluorescence for CRISPLD2. Coronal sections from the cerebrum of sham rats $(\mathbf{a}-\mathbf{c}, \mathbf{j}-\mathbf{I})$ and $2 \mathrm{VO}$ rats $(\mathbf{d}-\mathbf{i}, \mathbf{m}-\mathbf{r})$ on day 28 after surgery were immunostained with anti-CRISPLD2 antibody (green; color in online version only) together with anti-GFAP antibody (red). Nuclei were stained with 4'-6-diamidino-2-phenylindole (blue). Representative images in the paramedian corpus callosum (a-i) and cerebral cortex (cingulate cortex; j-r) are shown. Positive immunoreactivity for CRISPLD2 was blocked in the antigen competition experiments $(\mathbf{g}, \mathbf{i}, \mathbf{p}, \mathbf{r})$. Cells expressing CRISPLD2 in the cerebrum of the $2 \mathrm{VO}$ rats were similar to those in the sham rats on days 1,7 , and 28 after surgery. Scale bar $=10 \mu \mathrm{m} . \mathbf{s}, \mathbf{t}$ Western blotting

ruption of the $\mathrm{BBB}$ is observed in chronic cerebral hypoperfusion animals as well as in patients with WMLs [2731]. Endothelial activation and an increase in biomarkers of endothelial dysfunction are observed in patients with small vessel disease such as lacunar infarction and leukoaraiosis [32-34]. Our findings suggest that endothelial dysfunction has an important role in the development of WMLs in the $2 \mathrm{VO}$ rats.

Novel Genes and WML Development in Chronic Cerebral Hypoperfusion Rat

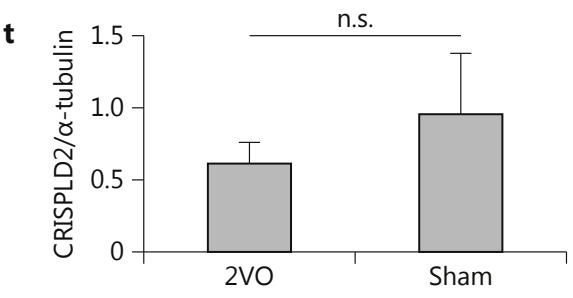

for CRISPLD2. s Representative images of the corpus callosum immunoreactive for CRISPLD2. Total proteins extracted from the corpus callosum of $2 \mathrm{VO}$ rats (lanes 1 and 2) or sham rats (lanes 3 and 4) on day 7 after surgery were analyzed by Western blotting with the anti-CRISPLD2 antibody (upper panel). After the detection, the same membrane was reprobed with the anti- $\alpha$-tubulin antibody (lower panel). $\mathbf{t}$ For quantification, the CRISPLD2 protein level relative to $a$-tubulin was determined by densitometry. n.s. $=$ Not significant. The difference between the $2 \mathrm{VO}$ rats $(\mathrm{n}=5)$ and the sham rats $(n=6)$ was not significant $(0.61 \pm 0.15$ vs. 0.96 \pm 0.42 vessels $/ 0.6 \mathrm{~mm}^{2}, \mathrm{p}=0.17$, Mann-Whitney $U$ test $)$.

The inwardly rectifying $\mathrm{K}^{+}$channel Kir6.1, encoded by the Kcnj8 gene, is expressed in vascular endothelial cells and vascular smooth muscle cells, and forms ATP-sensitive $\mathrm{K}^{+}$channels by coupling with a sulfonylurea receptor 2B [35-37]. Kir6.1 is also expressed in astrocytes [38]. A study of KCNJ8 null mice indicated that Kir6.1-containing $\mathrm{K}^{+}$channels are critical for the regulation of vascular tonus and for vasodilation. The Cx40/GJA5 protein, encoded by Gja5 gene, is a gap junction protein $[39,40]$. 
Cx40/GJA5 is expressed in endothelial cells, smooth muscle cells of arteries including cerebral arteries, and the myocardium [41-44]. Cx40/GJA5 expressed in endothelial cells plays a role in vasodilation, like nitric oxide and prostaglandins [45-48]. In addition, Fang et al. [49] reported that Cx40/GJA5 is necessary for postischemic tissue survival and reperfusion because $\mathrm{Cx} 40$-deficient mice experience a severe reduction in limb perfusion and exhibit profound and rapid failure of ischemic limb survival after femoral-saphenous artery-vein pair resection of a unilateral hindlimb compared to wild-type mice. The recovery of CBF values in $2 \mathrm{VO}$ rats between days 1 and 7 after surgery despite permanent occlusion of the bilateral common carotid arteries in the present study suggests the existence of compensatory mechanisms. Compensatory blood flow may be provided through artery dilation, recruitment of nonperfused capillaries, remodeling of microvessels, and arteriogenesis [12]. We speculate that Kir6.1 and Cx40/GJA5 are associated with the regulation of $\mathrm{CBF}$ in $2 \mathrm{VO}$ rats between days 1 and 7 after surgery via vasodilation.

vWF is a multimeric glycoprotein that is exclusively synthesized in endothelial cells and megakaryocytes [50]. Along with serving as a protective carrier molecule for clotting factor VIII, its main function is mediating initial platelet adhesion at sites of vascular injury [51]. Our finding that the upregulation of $\mathrm{Vwf}$ was associated with neuropathologic changes in the corpus callosum after day 7 suggests that $\mathrm{vWF}$ is associated with the development of WMLs. Recent findings that the severity of WMLs is associated with increased plasma levels, and activity of vWF in elderly people support our hypothesis $[33,34]$. The role of $\mathrm{vWF}$ in the development of WMLs remains unclear, although it has been reported that vWF-deficient mice are protected from brain ischemia/reperfusion injury, indicating that $\mathrm{vWF}$ is critically involved in cerebral ischemia [51-53]. BBB permeability in experimental allergic encephalomyelitis is significantly increased in mice with a disrupted Vwf gene compared with wild-type mice, indicating that vWF negatively regulates $\mathrm{BBB}$ permeability [54]. We speculate that $\mathrm{VWF}$ is associated with regulation of the BBB in the development of WMLs.

Permanent occlusion of the rodent unilateral middle cerebral artery (MCAO) causes cerebral infarction in the ipsilateral hemisphere due to cessation of blood flow. In $2 \mathrm{VO}$ rats, $\mathrm{CBF}$ is decreased but maintained, and there is no infarction in the brain, as demonstrated in the present study and by Farkas et al. [12]. Hori et al. [55] investigated gene expression profiles in the brain of the MCAO mouse by gene expression microarray analysis, and re- ported upregulation of Kcnj8, Gja5, B-cell chronic lymphocytic leukemia/lymphoma 6 (Bcl6b)/Bcl6-associated zinc finger protein (BAZF), and crispld2/late gestation lung 1 (Lgl1) genes among the differentially expressed genes in the ischemic hemisphere $24 \mathrm{~h}$ after MCAO. Both our findings and theirs suggest that Kcnj8, Gja5, Bcl6b/ BAZF, and Crispld2/Lgl1 genes are induced in the acute phase of ischemia by both hypoperfusion and nonperfusion. In contrast, they reported downregulation of Ptprb/ VE-PTP in the ischemic hemisphere $24 \mathrm{~h}$ after MCAO, whereas in the present study Ptprb/VE-PTP was upregulated on day 1 [55]. We speculate that Ptprb/VE-PTP expression is dysregulated differently in hypoperfusion than in nonperfusion. Downregulation of PTPRB/VEPTP expression enhances endothelial cell permeability, augments leukocyte transmigration, and inhibits VEcadherin-mediated adhesion, indicating that VE-PTP is required for endothelial cell contact integrity [56]. These findings suggest that differences in the expression of PTPRB/VE-PTP are associated with differences in neuropathologic changes, such as infarct.

CRISPLD2/Lgl1, a glycoprotein, was identified in the fibroblasts of fetal rat lung $[57,58]$. The expression of the Crispld2 gene is high in the adult rat lung, heart, and spleen, and in human leukocytes, lung, heart, and intestine, but low in the human brain $[57,59]$. CRISPLD2/Lg11 null mice are embryonic lethal by embryonic day 9.5 [60]. CRISPLD2/Lgl1 heterozygous knockout mice appear grossly normal, but lung maturation is delayed and ureteric bud branching is reduced at the fetal stage $[60,61]$. Chiquet et al. [62] reported an association between the CRISPLD2 gene and nonsyndromic cleft lip with or without cleft palate. Yuan et al. [63] reported that knockdown of crispld 2 results in aberrant patterning of neural crest cells in zebrafish. These findings suggest an essential role of CRISPLD2/Lgl1 in the development of various tissues, including the central nervous system. The function of CRISPLD2/Lgl1 in the central nervous system of adult animals and the role of CRISPLD2/Lgl1 in ischemic conditions, however, remain to be elucidated. Our findings that CRISPLD2/Lgl1 was expressed in astrocytes suggest that the induction of CRISPLD2/Lgl1 is associated with the activation of astrocytes in the cerebral white matter in the acute phase of cerebral ischemia.

TRAPPC6A is a subunit of the transport protein particle (TRAPP) I and II complexes. TRAPP complexes are essential for endoplasmic reticulum-to-Golgi (TRAPP I) and intra-Golgi (TRAPP II) vesicle trafficking [64, 65]. Mutations of the Trappc6a gene lead to defects in melanosome formation, implicating the involvement of mam- 
malian TRAPPC6A in vesicle trafficking during melanosome biogenesis [66]. Although the Trappc6a gene is widely expressed, including in the brain [66], the localization and role of TRAPPC6A in the brain remain to be elucidated. The present study revealed that TRAPPC6A localized in the cytoplasm of pyramidal neurons in the cortex and the hippocampus of the adult rat brain. The finding that TRAPPC6A was detected exclusively in neurons suggests that it is associated with neuronal dysfunction due to chronic hypoperfusion rather than the development of WMLs in the $2 \mathrm{VO}$ rat. The recent report that one haplotype from TRAPPC6A is associated with nonverbal reasoning in two cohorts of patients with Alzheimer's disease [67] interests us with regard to the association between TRAPPC6A and cognitive function.

BAZF, encoded by the Bcl6b gene, functions as a transcriptional repressor [68]. BAZF/Bcl6b mRNA in mouse tissues is expressed in the heart, the lung, and activated lymphocytes [68], and is also detected in human umbilical vein endothelial cells [69]. We demonstrated that $\mathrm{BAZF} / \mathrm{Bcl} 6 \mathrm{~b}$ mRNA was expressed in the cerebral white matter of the rat. Our findings that the expression of the $\mathrm{BAZF} / \mathrm{Bcl} 6 \mathrm{~b}$ gene was upregulated on day 1 , downregulated on day 7 , and returned to the normal level on day 28 , suggest that dysregulation of BAZF/Bcl6b gene expression in $2 \mathrm{VO}$ rats is associated with changes in $\mathrm{CBF}$. Impaired angiogenesis and capillary remodeling, which results in delayed wound healing, are observed in skinwounded BAZF-deficient mice [69], suggesting that $\mathrm{BAZF} / \mathrm{BCL} 6 \mathrm{~B}$ plays a role in tissue repair and angiogenesis. We speculate that $\mathrm{BAZF} / \mathrm{BCL} 6 \mathrm{~B}$ has a protective role against acute ischemic damage in $2 \mathrm{VO}$ rats.

In the present study, we demonstrated that genes dysregulated by chronic cerebral hypoperfusion were expressed in endothelial cells, glial cells, and neurons, which form the neurovascular unit. The neurovascular unit controls $\mathrm{BBB}$ permeability and $\mathrm{CBF}$, and maintains the chemical composition of the neuronal 'milieu', which is required for proper functioning of neuronal circuits [70]. Ueno et al. [29] reported that chronic cerebral hypoperfusion induces an increase in $\mathrm{BBB}$ permeability to horseradish peroxidase, which appears by day 1 , peaks on day 3 , and recovers by day 7 in the corpus callosum of $2 \mathrm{VO}$ rats. In chronic cerebral hypoperfusion, decreased $\mathrm{CBF}$ also recovers by day 7 , while WMLs consistently develop, as demonstrated in the present study. In addition, we demonstrated that the expression of genes in the corpus callosum of $2 \mathrm{VO}$ rats on day 7 was dysregulated based on $\mathrm{CBF}$ values and neuropathologic changes. We also demonstrated that there are few differences in the expression of proteins encoded by these dysregulated genes between $2 \mathrm{VO}$ and sham rats, suggesting that insufficient posttranscriptional control, translation, or posttranslational modifications of these genes is associated with dysfunction of the neurovascular unit. A comprehensive understanding of the pathophysiology of the neurovascular unit in chronic cerebral hypoperfusion is crucial toward the discovery of therapeutic targets.

\section{Acknowledgments}

This research was supported in part by grants from the Ministry of Education, Science, Sports, and Culture, Grant-in-Aid for Scientific Research (C): No. 20591005 (T.K.), 23591251 (T.K.), 24592137 (M.F.), and 25460905 (N.K.). We are grateful to Mariko Ono and Kaori Hirano for their excellent technical assistance. We would also like to thank Eisaku Ohama for histologic analysis and Yoshiyuki Tsukamoto for technical advice about gene expression microarray.

\section{Disclosure Statement}

The authors declare no conflicts of interest.

\section{References}

1 Breteler MM, van Swieten JC, Bots ML, Grobbee DE, Claus JJ, van den Hout JH, et al: Cerebral white matter lesions, vascular risk factors, and cognitive function in a populationbased study: The Rotterdam Study. Neurology 1994;44:1246-1246.

2 Kimura N, Nakama H, Nakamura K, Aso Y, Kumamoto T: Relationship between white matter lesions and progression of cognitive decline in Alzheimer's disease. Dement Geriatr Cogn Dis Extra 2013;3:96-101.
3 Moorhouse P, Rockwood K: Vascular cognitive impairment: current concepts and clinical developments. Lancet Neurol 2008;7:246255.

-4 O’Brien JT, Erkinjuntti T, Reisberg B, Roman G, Sawada T, Pantoni L, et al: Vascular cognitive impairment. Lancet Neurol 2003;2:8998.

-5 Román GC, Erkinjuntti T, Wallin A, Pantoni L, Chui HC: Subcortical ischaemic vascular dementia. Lancet Neurol 2002;1:426-436.
-6 Burton EJ, Kenny RA, O’Brien J, Stephens S, Bradbury M, et al: White matter hyperintensities are associated with impairment of memory, attention, and global cognitive performance in older stroke patients. Stroke 2004; 35:1270-1275.

7 Black S, Gao F, Bilbao J: Understanding white matter disease: imaging-pathological correlations in vascular cognitive impairment. Stroke 2009;40:S48-S52.
Novel Genes and WML Development in Chronic Cerebral Hypoperfusion Rat 
8 Fazekas F, Kleinert R, Offenbacher H, 20 Pappas BA, de la Torre JC, Davidson CM, Schmidt R, Kleinert G, Payer F, et al: Pathologic correlates of incidental MRI white matter signal hyperintensities. Neurology 1993; 43:1683-1689.

-9 Tomimoto H, Akiguchi I, Akiyama H, Kimura J, Yanagihara T: T-cell infiltration and expression of MHC class 11 antigen by macrophages and microglia in a heterogeneous group in leukoencephalopathy. Am J Pathol 1993; 143:579-586.

10 van Swieten JC, van den Hout JH, van Ketel BA, Hijdra A, Wokke JH, van Gijn J: Periventricular lesions in the white matter on magnetic resonance imaging in the elderly. A morphometric correlation with arteriolosclerosis and dilated perivascular spaces. Brain 1991;114:761-774.

11 Pantoni L, Garcia JH: Cognitive impairment and cellular/vascular changes in the cerebral white matter. Ann NY Acad Sci 1997;826:92102.

12 Farkas E, Luiten PGM, Bari F: Permanent, bilateral common carotid artery occlusion in the rat: a model for chronic cerebral hypoperfusion-related neurodegenerative diseases. Brain Res Rev 2007;54:162-180.

13 Lee JJH, Park SSY, Shin YYW, Hong KWK, Kim CD, Sung S-M, et al: Neuroprotection by cilostazol, a phosphodiesterase type 3 inhibitor, against apoptotic white matter changes in rat after chronic cerebral hypoperfusion. Brain Res 2006;1082:182-191.

14 Otori T, Katsumata T, Muramatsu H, Kashiwagi F, Katayama Y, Terashi A: Long-term measurement of cerebral blood flow and metabolism in a rat chronic hypoperfusion model. Clin Exp Pharmacol Physiol 2003;30:266272.

15 Schmidt-Kastner R, Aguirre-Chen C, Saul I, Yick L, Hamasaki D, Busto R, et al: Astrocytes react to oligemia in the forebrain induced by chronic bilateral common carotid artery occlusion in rats. Brain Res 2005;1052:28-39.

16 Tomimoto H, Ihara M, Wakita H, Ohtani R, Lin JX, Akiguchi I, et al: Chronic cerebral hypoperfusion induces white matter lesions and loss of oligodendroglia with DNA fragmentation in the rat. Acta Neuropathol 2003;106: 527-534.

17 Wakita H, Tomimoto H, Akiguchi I, Kimura $\mathrm{J}$ : Glial activation and white matter changes in the rat brain induced by chronic cerebral hypoperfusion: an immunohistochemical study. Acta Neuropathol 1994;87:484-492.

$\checkmark 18$ De Jong GI, Farkas E, Stienstra CM, Plass JRM, Keijser JN, De La Torre JC, et al: Cerebral hypoperfusion yields capillary damage in the hippocampal CA1 area that correlates with spatial memory impairment. Neuroscience 1999;91:203-210.

-19 Ohta H, Nishikawa H, Kimura H, Anayama $\mathrm{H}$, Miyamoto M: Chronic cerebral hypoperfusion by permanent internal carotid ligation produces learning impairment without brain damage in rats. Neuroscience 1997;79:10391050. Keyes MT, Fortin T: Chronic reduction of cerebral blood flow in the adult rat: late-emerging CA1 cell loss and memory dysfunction. Brain Res 1996;708:50-58.

21 Sarti C, Pantoni L, Bartolini L, Inzitari D: Cognitive impairment and chronic cerebral hypoperfusion: what can be learned from experimental models. J Neurol Sci 2002;203204:263-266.

22 Harada H, Wang Y, Mishima Y, Uehara N, Makaya T, Kano T: A novel method of detecting $\mathrm{rCBF}$ with laser-Doppler flowmetry without cranial window through the skull for a $\mathrm{MCAO}$ rat model. Brain Res Brain Res Protoc 2005; 14:165-170.

23 Yoshimoto T, Matsuura K, Karnan S, Tagawa $\mathrm{H}$, Nakada C, Tanigawa M, Tsukamoto $\mathrm{Y}$, Uchida T, Kashima K, Akizuki S, Takeuchi I, Sato F, Mimata H, Seto M, Moriyama M: High-resolution analysis of DNA copy number alterations and gene expression in renal clear cell carcinoma. J Pathol 2007;213:392401.

24 Nakamura K, Tsukamoto Y, Hijiya N, Higuchi Y, Yano S, Yokoyama S, et al: Induction of GNE in myofibers after muscle injury. Pathobiology 2010;77:191-199.

25 Dominguez MG, Hughes VC, Pan L, Simmons M, Daly C, Anderson K, et al: Vascular endothelial tyrosine phosphatase (VE-PTP)null mice undergo vasculogenesis but die embryonically because of defects in angiogenesis. Proc Natl Acad Sci USA 2007;104:32433248.

26 Fachinger G, Deutsch U, Risau W: Functional interaction of vascular endothelial-proteintyrosine phosphatase with the angiopoietin receptor Tie-2. Oncogene 1999;18:59485953.

27 Nakaji K, Ihara M, Takahashi C, Itohara S, Noda M, Takahashi R, et al: Matrix metalloproteinase- 2 plays a critical role in the pathogenesis of white matter lesions after chronic cerebral hypoperfusion in rodents. Stroke 2006;37:2816-2823.

28 Sood R, Yang Y, Taheri S, Candelario-Jalil E, Estrada EY, Walker EJ, et al: Increased apparent diffusion coefficients on MRI linked with matrix metalloproteinases and edema in white matter after bilateral carotid artery occlusion in rats. J Cereb Blood Flow Metab 2009:29:308-316.

29 Ueno M, Tomimoto H, Akiguchi I, Wakita H, Sakamoto H: Blood-brain barrier disruption in white matter lesions in a rat model of chronic cerebral hypoperfusion. J Cereb Blood Flow Metab 2002;22:97-104.

30 Ueno Y, Zhang N, Miyamoto N, Tanaka R, Hattori N, Urabe T: Edaravone attenuates white matter lesions through endothelial protection in a rat chronic hypoperfusion model. Neuroscience 2009;162:317-327.

31 Yang Y, Rosenberg GA: Blood-brain barrier breakdown in acute and chronic cerebrovascular disease. Stroke 2011;42:3323-3328.
2 Hassan A, Hunt BJ, O’Sullivan M, Parmar K, Bamford JM, Briley D, et al: Markers of endothelial dysfunction in lacunar infarction and ischaemic leukoaraiosis. Brain 2003;126:424432.

33 Kearney-Schwartz A, Rossignol P, Bracard S, Felblinger J, Fay R, Boivin JM, et al: Vascular structure and function is correlated to cognitive performance and white matter hyperintensities in older hypertensive patients with subjective memory complaints. Stroke 2009; 40:1229-1236

34 Wada M, Takahashi Y, Iseki C, Kawanami T, Daimon M, Kato T: Plasma fibrinogen, global cognitive function, and cerebral small vessel disease: results of a cross-sectional study in community-dwelling Japanese elderly. Intern Med 2011;50:999-1007.

35 Li L, Wu J, Jiang C: Differential expression of Kir6.1 and SUR2B mRNAs in the vasculature of various tissues in rats. J Membr Biol 2003; 196:61-69.

36 Malester B, Tong X, Ghiu I, Kontogeorgis A, Gutstein DE, Xu J, et al: Transgenic expression of a dominant negative $\mathrm{K}_{\mathrm{ATP}}$ channel subunit in the mouse endothelium: effects on coronary flow and endothelin-1 secretion. FASEB J 2007;21:2162-2172.

37 Seino S, Miki T: Gene targeting approach to clarification of ion channel function: studies of Kir6.x null mice. J Physiol 2004;554:295300.

38 Thomzig A, Wenzel M, Karschin C, Eaton MJ, Skatchkov SN, Karschin A, et al: Kir6.1 is the principal pore-forming subunit of astrocyte but not neuronal plasma membrane KATP channels. Mol Cell Neurosci 2001;18: 671-690.

-39 Haefliger J, Bruzzone R, Jenkins N, Gilbert DJ, Copeland NG, Paul DL: Four novel members of the connexin family of gap junction proteins. Molecular cloning, expression, and chromosome mapping. J Biol Chem 1992; 267:2057-2064.

40 Hennemann $\mathrm{H}$, Suchyna T, Lichtenberg-Fraté H, Jungbluth S, Dahl E, Schwarz J, Nicholson $\mathrm{BJ}$, Willecke $\mathrm{K}$ : Molecular cloning and functional expression of mouse connexin 40 , a second gap junction gene preferentially expressed in lung. J Cell Biol 1992;117:12991310.

41 Bastide B, Neyses L, Ganten D, Paul M, Willecke K, Traub O: Gap junction protein connexin 40 is preferentially expressed in vascular endothelium and conductive bundles of rat myocardium and is increased under hypertensive conditions. Circ Res 1993;73:1138-1149.

42 Bruzzone R, Haefliger JA, Gimlich RL, Paul DL: Connexin40, a component of gap junctions in vascular endothelium, is restricted in its ability to interact with other connexins. Mol Biol Cell 1993;4:7-20.

-43 Little TL, Beyer EC, Duling BR: Connexin 43 and connexin 40 gap junctional proteins are present in arteriolar smooth muscle and endothelium in vivo. Am J Physiol 1995; 268:H729-H739. 
-44 Yeh H-I, Dupont E, Coppen S, Rothery S, Severs NJ: Gap junction localization and connexin expression in cytochemically identified endothelial cells of arterial tissue. J Histochem Cytochem 1997;45:539-550.

45 Alonso F, Boittin F-X, Bény J-L, Haefliger J-A: Loss of connexin 40 is associated with decreased endothelium-dependent relaxations and eNOS levels in the mouse aorta. Am J Physiol Heart Circ Physiol 2010;299:H1365H1373.

46 de Wit C, Roos F, Bolz S-SS, Kirchhoff S, Krüger O, Willecke K, et al: Impaired conduction of vasodilation along arterioles in connexin40-deficient mice. Circ Res 2000;86: 649-655.

47 Mather S: Rapid endothelial cell-selective loading of connexin 40 antibody blocks endothelium-derived hyperpolarizing factor dilation in rat small mesenteric arteries. Circ Res 2005;97:399-407.

48 Milkau M, Köhler R, de Wit C: Crucial importance of the endothelial $\mathrm{K}+$ channel SK3 and connexin40 in arteriolar dilations during skeletal muscle contraction. FASEB J 2010;24: 3572-3579.

49 Fang JS, Angelov SN, Simon AM, Burt JM: $\mathrm{Cx} 40$ is required for, and cx37 limits, postischemic hindlimb perfusion, survival and recovery. J Vasc Res 2012;49:2-12.

50 Lip GY, Blann A: von Willebrand factor: a marker of endothelial dysfunction in vascular disorders? Cardiovasc Res 1997;34:255-265.

-51 De Meyer SF, Stoll G, Wagner DD, Kleinschnitz C: von Willebrand factor: an emerging target in stroke therapy. Stroke 2012;43: 599-606.

52 Kleinschnitz C, De Meyer SF, Schwarz T, Austinat M, Vanhoorelbeke K, Nieswandt B, et al: Deficiency of von Willebrand factor protects mice from ischemic stroke. Blood 2009, 113:3600-3603.
Zhao B-Q, Chauhan AK, Canault M, Patten IS, Yang JJ, Dockal M, et al: von Willebrand factor-cleaving protease ADAMTS13 reduces ischemic brain injury in experimental stroke. Blood 2009;114:3329-3334.

54 Noubade R, del Rio R, McElvany B, Zachary JF, Millward JM, Wagner DD, et al: von-Willebrand factor influences blood brain barrier permeability and brain inflammation in experimental allergic encephalomyelitis. Am J Pathol 2008;173:892-900.

55 Hori M, Nakamachi T, Rakwal R, Shibato J, Nakamura K, Wada Y, et al: Unraveling the ischemic brain transcriptome in a permanent middle cerebral artery occlusion mouse model by DNA microarray analysis. Dis Model Mech 2012;5:270-283.

56 Nottebaum AF, Cagna G, Winderlich M, Gamp AC, Linnepe R, Polaschegg C, et al: VEPTP maintains the endothelial barrier via plakoglobin and becomes dissociated from VE-cadherin by leukocytes and by VEGF. J Exp Med 2008;205:2929-2945.

57 Kaplan F, Ledoux P, Kassamali FQ, Gagnon S, Post M, Koehler D, et al: A novel developmentally regulated gene in lung mesenchyme: homology to a tumor-derived trypsin inhibitor. Am J Physiol 1999;276:L1027-L1036.

58 Oyewumi L, Kaplan F, Sweezey NB: Lgl1, a mesenchymal modulator of early lung branching morphogenesis, is a secreted glycoprotein imported by late gestation lung epithelial cells. Biochem J 2003;376:61-69.

59 Wang Z-Q, Xing W-M, Fan H-H, Wang K-S, Zhang H-K, Wang Q-W, et al: The novel lipopolysaccharide-binding protein CRISPLD2 is a critical serum protein to regulate endotoxin function. J Immunol 2009; 183:6646-6656.

60 Lan J, Ribeiro L, Mandeville I, Nadeau K, Bao $\mathrm{T}$, Cornejo S, et al: Inflammatory cytokines, goblet cell hyperplasia and altered lung mechanics in Lgl1+/- mice. Respir Res 2009;10:83

61 Quinlan J, Kaplan F, Sweezey N, Goodyer P. LGL1, a novel branching morphogen in developing kidney, is induced by retinoic acid. Am J Physiol Renal Physiol 2007;293:F987-F993.
62 Chiquet BT, Lidral AC, Stal S, Mulliken JB, Moreno LM, Arco-Burgos M, etal:CRISPLD2: a novel NSCLP candidate gene. Hum Mol Genet 2007;16:2241-2248.

63 Yuan Q, Chiquet BT, Devault L, Warman ML, Nakamura Y, Swindell EC, et al: Craniofacial abnormalities result from knock down of nonsyndromic clefting gene, crispld2, in zebrafish. Genesis 2012;50:871-881.

64 Sacher M, Barrowman J, Wang W, Horecka J, Zhang Y, Pypaert M, et al: TRAPP I implicated in the specificity of tethering in ER-toGolgi transport. Mol Cell 2001;7:433-442.

65 Sacher M, Kim Y-G, Lavie A, Oh B-H, Segev $\mathrm{N}$ : The TRAPP complex: insights into its architecture and function. Traffic 2008;9:20322042.

66 Gwynn B, Smith RS, Rowe LB, Taylor BA, Peters LL: A mouse TRAPP-related protein is involved in pigmentation. Genomics 2006;88: 196-203.

67 Hamilton G, Harris SE, Davies G, Liewald DC, Tenesa A, Starr JM, et al: Alzheimer's disease genes are associated with measures of cognitive ageing in the Lothian birth cohorts of 1921 and 1936. Int J Alzheimers Dis 2011; 2011:1-11.

68 Okabe S, Fukuda T, Ishibashi K, Kojima S, Okada S, Hatano M, et al: BAZF, a novel Bcl6 homolog, functions as a transcriptional repressor. Mol Cell Biol 1998;18:4235-4244.

-69 Ohnuki H, Inoue H, Takemori N, Nakayama H, Sakaue T, Fukuda S, et al: BAZF, a novel component of cullin3-based E3 ligase complex, mediates VEGFR and Notch cross-signaling in angiogenesis. Blood 2012;119:26882698.

70 Zlokovic BV: Neurovascular pathways to neurodegeneration in Alzheimer's disease and other disorders. Nat Rev Neurosci 2011; 12:723-738.
Novel Genes and WML Development in Chronic Cerebral Hypoperfusion Rat 